\title{
An Analysis of Conceptions of Learning English Among College Students in China
}

\author{
LUAN Lin \\ Beijing University of Posts and Telecommunications, Beijing, China
}

\begin{abstract}
In the field of second language acquisition, an increasing amount of research has been conducted on learner's beliefs. Few empirical studies, however, have been focused on students' conceptions of learning English (COLE). This study aims to assess conceptions of learning particularly in the domain of English. Data were collected through the COLE questionnaire among 284 college students in China. Seven factors of COLE are identified, such as "memorizing", "testing", "drill and practice", "increasing knowledge", "understanding", "application", and "seeing in a new way". These findings also provide some pedagogical implications for English language instructors and researchers.
\end{abstract}

Keywords: SLA, conceptions of learning, conceptions of language learning, college students

\section{Introduction}

In the field of second language acquisition (SLA), conceptions of language and language learning are regarded as "higher level category conditioning specific beliefs" and reflect learners' thinking about their language learning (Benson \& Lor, 1999). Although much of the research in the field of conceptions of learning has been particularly concerned with conceptions of learning science or mathematics, relatively few studies have been published on conceptions of learning English (ZHENG, LIANG, YANG, \& Tsai, 2016). The issue of how to promote students' conceptions of learning English (COLE) thus remains an essential issue for English language education. This study, situated in mainland China, attempts to explore the different dimensions of COLE in the field of SLA. It was expected to provide critical implications for English language instructors and deeper insights into the nature of the conceptions of language learning in the context of learning English as a foreign language (EFL).

\section{Literature Review}

\section{Conceptions of Language Learning}

Conceptions of learning refer to what students think learning is and what its outcomes might be (Ellis, Goodyear, Calvo, \& Prosser, 2008). A lot of research has been focused on learners' conceptions of learning in

\footnotetext{
* Acknowledgements: I would like to show my gratitude to all the reviewers and editors who have provided insightful comments and suggestions. I also want to acknowledge the valuable comments of Professor Chun-ping ZHENG and Professor Zhi-hong LU. This study is funded by the Humanities and Social Sciences Project "Research on Multidimensional Assessment for a Web-based English Audio-video Speaking Course" (12YJA740052), supported by the Ministry of Education in China.

LUAN Lin, lecturer, M.A., School of Humanities, Beijing University of Posts and Telecommunications, Beijing, China.
} 
the past few decades (e.g., Säljö, 1979; Tsai, 2004; Tsai, Ho, LIANG, \& LIN, 2011; Vermunt \& van Rijswijk, 1988; Vermunt \& Vermetten, 2004). Drawing on the early categorizations of conceptions of learning (e.g., Marshall, Summer, Woolnough, 1999; Marton, Dall'Alba, \& Beaty, 1993; Säljö, 1979), Tsai (2004) classified Taiwanese high school students' conceptions of learning in the domain of science (COLS) into seven categories, including "memorizing", "preparing for tests", "calculating and practicing tutorial problems", "increase of knowledge", "applying", "understanding", and "seeing in a new way".

In the field of SLA, the notion of conceptions of language and language learning is proposed by Benson and Lor (1999), who defined conceptions of learning are concerned with what the learners think a foreign language is and what process of learning a foreign language consists of in the context of foreign language learning. White (1999) investigated learners' conceptions in relation to their distance language learning by using a phenomenographic research approach. In a qualitative study conducted by ZHENG and her colleagues, conceptions of learning English were categorized as: (1) memorizing; (2) testing; (3) drill and practice; (4) grammar, vocabulary, and pronunciation; (5) increasing one's knowledge; (6) application and communication; and (7) understanding and seeing in a new way (ZHENG, LIANG, YANG, \& Tsai, 2016). Although there were substantial investigations into learners' conceptions across different fields of enquiry and at different educational levels, limited research findings have been reported on conceptions of learning among EFL learners. The present study therefore addresses this research gap by measuring the students' conception of learning and exploring the categorization among the different dimensions of students' conceptions of learning within the field of EFL learning. The study answers the following research question: What are the students' discipline-specific conceptions of learning English?

\section{Method}

\section{Participants}

The participants consisted of 284 college students in China. All the students were recruited from the course of "College English", which is one of the compulsory courses for undergraduates at the university. All of the participants were volunteered to respond to the instrument of COLE anonymously at the end of the second semester in 2014. Before taking part in this study, all the participants had received over six years of formal English education and passed the English test for the National College Entrance Examination in China.

\section{Instruments}

This present research employed "Conceptions of Learning English Survey" (COLE) developed by ZHENG and her colleagues (2016) to investigate conceptions of learning English among Chinese college students, which was designed in light of the seven categories of the Conceptions of Learning Science (COLS) proposed by Tsai (2004; 2008). COLE, a five-point Likert scale with a total of 30 items, contains two to eight items in each of the seven subscales. Table 1 demonstrates the definitions for seven factors of COLE. 
Table 1

Information About the Seven Factors in the COLE

\begin{tabular}{|c|c|c|}
\hline & Factor names & Definitions \\
\hline 1 & Memorizing & $\begin{array}{l}\text { Learning English means memorizing the word patterns and phrases, grammar concepts, and } \\
\text { sentence structures found in an English textbook. }\end{array}$ \\
\hline 2 & Testing & Learning English means getting high scores on examinations. \\
\hline 3 & Drill and practice & Learning English means constantly practicing listening, speaking, reading, and writing. \\
\hline 4 & $\begin{array}{l}\text { Grammar, vocabulary and } \\
\text { pronunciation }\end{array}$ & $\begin{array}{l}\text { Learning English means acquiring new vocabulary, appropriate pronunciation, and understanding } \\
\text { the connection between grammar rules. }\end{array}$ \\
\hline 5 & Increase one's knowledge & Learning English means acquiring and accumulating knowledge. \\
\hline 6 & $\begin{array}{l}\text { Application and } \\
\text { communication }\end{array}$ & $\begin{array}{l}\text { The purpose of learning English is learning how to retrieve what had been learned (accumulated } \\
\text { and stored) and use it. }\end{array}$ \\
\hline 7 & $\begin{array}{l}\text { Understanding and seeing } \\
\text { in a new way }\end{array}$ & $\begin{array}{l}\text { Learning English means to understand language differences and subject matters or issues related to } \\
\text { other countries by integrating and constructing theoretically consistent knowledge structures in } \\
\text { English. Or, learning English also aims to construct a new perspective, to gain a better } \\
\text { understanding of reality by abstracting meaning from what is presented, and to acquire English } \\
\text { knowledge by getting a new way to clarify linguistic and multi-cultural phenomena. }\end{array}$ \\
\hline
\end{tabular}

\section{Data Collection}

For each selected class, its English teacher confirmed that the students volunteered to respond to the questionnaires in one setting and all of them completed the questionnaires of COLE anonymously. A total of 248 students' responses were analyzed by evaluating their COLE.

\section{Data Analysis}

A confirmatory factor analysis (CFA) was employed to validate the measurement model, in which construct validity and reliability were assessed. The construct validity deals with whether the measured items can well represent the survey constructs (i.e., the analysis of convergent validity) and whether the constructs are independent of each other (i.e., the analysis of discriminant validity). The evaluation of the model fit was then employed to verify the structure of the survey and the Cronbach's alpha was reported to assess the internal consistency of each survey.

\section{Results}

In order to verify the validity of COLE survey, a confirmatory factor analysis (CFA) was conducted. According to the CFA result, all the loading values of measured items are significant and higher than 0.50 . Besides, the average variance extracted (AVE) values of all the constructs exceed the cutoff values of 0.50 , ranging from 0.52 to 0.61 . Moreover, the composite reliability (CR) values are also larger than 0.70 , ranging from 0.73 to 0.90 . Then, the Cronbach's alpha values for these factors are also calculated and the reliability coefficients for all the constructs are above 0.70 , from the lowest 0.70 to the highest 0.90 , respectively. The overall Cronbach's alpha is 0.83 , which further indicates sufficient internal consistency of the survey items. With respect to the goodness-of-fit (GOF) of the model, the ratio of chi-square to degrees of freedom is $2.17, \mathrm{CFI}=$ $0.90, \mathrm{GFI}=0.85, \mathrm{AGFI}=0.81, \mathrm{NFI}=0.84, \mathrm{IFI}=0.91, \mathrm{TLI}=0.89$, and $\mathrm{RMSEA}=0.06$. The statistics obtained indicate a good model fit of our proposed model (e.g., Browne \& Cudeck, 1993; Khine, 2013) and further confirm the validity and reliability of the research instrument. 


\section{Discussion}

This present study was conducted to investigate Chinese college students' conceptions of learning English. The study adopted ZHENG and her colleagues' (2016) COLE questionnaire to assess the students' conception of learning English. The findings through confirmatory factor analyze revealed that students' conceptions of learning English displayed seven similar factor structures as previous study (ZHENG, LIANG, YANG, \& Tsai, 2016), including "memorizing", "testing”, "drill and practice", "increasing knowledge”, "understanding”, "application", and "seeing in a new way". By inspecting the fit indices of this model, the seven-factor result of COLE was well-supported with satisfactory reliability and validity, which confirmed the generality of this instrument so that it can be replicated with similar research and sample groups.

Although the CFA results revealed similar factor structures to the previous study (ZHENG, LIANG, YANG, \& Tsai, 2016), a little inconsistency was found with the factor "grammar, vocabulary, and pronunciation" being eliminated. The possible reason for the change is that this conception could also be considered as a part of the conception "memorizing", defining as "memorizing the word patterns and phrases, grammar concepts, and sentence structures found in an English textbook". For Chinese learners, memorization is a central part of their language learning process, but not the whole of it (GU \& Johnson, 1996). Learners' devotion to memorizing grammar or vocabulary may be possibly related to the Chinese sociocultural context, featuring with grammar-oriented tradition in teaching (e.g., HU, 2002; RAO, 2010; YU, 2001) or the emphasis on grammar and vocabulary assessments in various tests in China (e.g., HU, 2003; PAN \& Block, 2011). Another inconsistency was also identified as the conception of "understanding and seeing in a new way" in ZHENG et al.'s study (2016) was divided into two individual dimensions known as "understanding" and "seeing in a new way" in this study. The plausible explanation for this change is that Chinese learners may regard conceptions of "understanding" and "seeing in a new way" as being equally important for learning English but differ in their significance. As a result of Confucian Heritage Culture, it could be possible to conclude that Chinese college students may need to accumulate enough basic knowledge as well as to understand it, which ultimately helps them to construct a new perspective to clarify linguistic and multi-cultural phenomena.

\section{Conclusion}

The findings reveal that students' COLE including seven factors, including "memorizing", "testing”, "drill and practice", "increasing knowledge", "understanding", "application", and "seeing in a new way". This inquiry provides some important pedagogical implications. First, due to the complexity of learner beliefs (Benson \& Lor, 1999), the instrument of COLE validated in this study could help English language educators and researchers gain a deeper insight into English language learners' conceptions in the process of course design, so as to provide more timely and appropriate guidance in their classroom teaching. Second, the result of CFA could be used as a reference for a researcher to consider when redesigning the questionnaire in the future. In addition, because this inquiry was limited to exploring COLE among college students in China, more cross-cultural comparisons of COLE may be needed in other EFL countries. Another limitation as well as a suggestion for future studies is to combine more in-depth qualitative studies through interviews, observations or other qualitative methods are recommended to capture the complex dynamics of learner beliefs further. 


\section{References}

Benson, P., \& Lor, W. (1999). Conceptions of language and language learning. System, 27(4), 459-472.

Browne, M. W., \& Cudeck, R. (1993). Alternative ways of assessing model fit. Sage Focus Editions, 154, 136.

Ellis, R. A., Goodyear, P., Calvo, R. A., \& Prosser, M. (2008). Engineering students' conceptions of and approaches to learning through discussions in face-to-face and online contexts. Learning and Instruction, 18(3), 267-282.

GU, Y., \& Johnson, R. K. (1996). Vocabulary learning strategies and language learning outcomes. Language Learning, 46(4), 643-679.

HU, G. (2002). Potential cultural resistance to pedagogical imports: The case of communicative language teaching in China. Language Culture and Curriculum, 15(2), 93-105.

HU, G. (2003). English language teaching in China: Regional differences and contributing factors. Journal of Multilingual and Multicultural Development, 24(4), 290-318.

Khine, M. S. (Ed.). (2013). Application of structural equation modeling in educational research and practice. Rotterdam: Sense Publishers.

Marshall, D., Summer, M., \& Woolnough, B. (1999). Students' conceptions of learning in an engineering context. Higher Education, 38(3), 291-309.

Marton, F., Dall'Alba, G., \& Beaty, E. (1993). Conceptions of learning. International Journal of Educational Research, 19, 277-300.

PAN, L., \& Block, D. (2011). English as a "global language” in China: An investigation into learners' and teachers' language beliefs. System, 39(3), 391-402.

RAO, Z. (2010). Chinese students' perceptions of native English-speaking teachers in EFL teaching. Journal of Multilingual and Multicultural Development, 31(1), 55-68.

Saljo, R. (1979). Learning in the learner's perspective. I. Some common sense conceptions. Reports from the Department of Education, University of Göteborg, No. 76.

Tsai, C. C. (2004). Conceptions of learning science among high school students in Taiwan: A phenomenographic analysis. International Journal of Science Education, 26(14), 1733-1750.

Tsai, C. C., \& KUO, P. C. (2008). Cram school students' conceptions of learning and learning science in Taiwan. International Journal of Science Education, 30(3), 353-375.

Tsai, C. C., Ho, H. N. J., LIANG, J. C., \& LIN, H. M. (2011). Scientific epistemic beliefs, conceptions of learning science and self-efficacy of learning science among high school students. Learning and Instruction, 21(6), 757-769.

Vermunt, J. D., \& Van Rijswijk, F. A. (1988). Analysis and development of students' skill in self-regulated learning. Higher Education, 17(6), 647-682.

Vermunt, J. D., \& Vermetten, Y. J. (2004). Patterns in student learning: Relationships between learning strategies, conceptions of learning, and learning orientations. Educational Psychology Review, 16(4), 359-384.

White, C. (1999). Expectations and emergent beliefs of self-instructed language learners. System, 27(4), 443-457.

YANG, Y. F., \& Tsai, C. C. (2010). Conceptions of and approaches to learning through online peer assessment. Learning and Instruction, 20(1), 72-83.

YU, L. (2001). Communicative language teaching in China: Progress and resistance. Tesol Quarterly, 35(1), 194-198.

ZHENG, C., LIANG, J. C., YANG, Y. F., \& Tsai, C. C. (2016). The relationship between Chinese university students' conceptions of language learning and their online self-regulation. System, 57, 66-78. 